\title{
Diagnostic criteria for diabetes revisited: making use of combined criteria
}

\author{
Ali Parappil1, Suhail AR Doi*2,3 and Kamal AS Al-Shoumer ${ }^{2,3}$
}

Address: ${ }^{1}$ Division of Medicine, Jahra Hospital, Kuwait, ${ }^{2}$ Division of Endocrinology and Metabolic Medicine, Faculty of Medicine, Kuwait and ${ }^{3}$ Mubarak Al-Kabeer Hospital, Jabriya, Kuwait

E-mail: Ali Parappil - alip1@myrealbox.com; Suhail AR Doi* - sardoi@myrealbox.com; Kamal AS Al-Shoumer - kshoumer@hsc.kuniv.edu.kw * Corresponding author

Published: I February 2002

BMC Endocrine Disorders 2002, 2:1
Received: 14 November 200 |

Accepted: I February 2002

This article is available from: http://www.biomedcentral.com//472-6823/2/I

(c) 2002 Parappil et al; licensee BioMed Central Ltd. Verbatim copying and redistribution of this article are permitted in any medium for any purpose, provided this notice is preserved along with the article's original URL.

\begin{abstract}
Background: Existing cut-offs for fasting plasma glucose (FPG) and post-load glucose (2hPG) criteria are not equivalent in the diagnosis of diabetes and glucose intolerance. Adjusting cut-offs of single measurements have not helped so we undertook this project to see if they could be complementary.

Methods: We performed oral glucose tolerance tests and mean levels of hemoglobin Alc (HbAlc) measurements on 43 patients referred to a diabetes clinic for possible diabetes. Results of single and combined use of the FPG and $2 \mathrm{hPG}$ criteria were evaluated against the levels of $\mathrm{HbAlc}$ and results re-interpreted in the light of existing reports in the literature.

Results: Our results confirm that the FPG and the $2 \mathrm{hPG}$, being specific and sensitive respectively for the presence of glucose intolerance or diabetes, are not equivalent. They are shown to be indeed complementary and a re-definition of diagnostic criteria based on their combined use is proposed.

Conclusions: We conclude that altering single measurement cut-offs for the diagnosis of diabetes and altered glucose tolerance will not result in better outcomes. We present the case for a combined criteria in the diagnosis and definition of diabetes with a FPG $\geq 7 \mathrm{mmol} / \mathrm{L}$ AND 2-hour glucose $\geq 7.8 \mathrm{mmol} / \mathrm{L}$ being used to define diabetes while a $\mathrm{FPG}<7 \mathrm{mmol} / \mathrm{L}$ AND 2-hour glucose $<7.8 \mathrm{mmol} / \mathrm{L}$ being used to define normality. Discordant values will define impaired glucose tolerance (IGT). This proposal requires prospective evaluation in a large cohort.
\end{abstract}

\section{Introduction}

Prior to the National Diabetes Data Group (NDDG) diagnostic criteria for diabetes in 1979 , there were many different sets of criteria used to diagnose diabetes [1] resulting in a prevalence of diabetes that differed depending on the criteria used. In 1979, the NDDG recommended one set of criteria [2] which was modified by the World Health Organization (WHO) [3] in 1980. These criteria were selected based on the results of 3 prospective studies [4-6] in which subjects without diabetic retinopathy were given oral glucose tolerance tests and followed for 3 to 8 years, at which time $6 \%$ of them had developed this complication [7]. Based on the 2-hour post glucose (2hPG) values of these individuals, a 2-hour glucose concentration of $\geq 11.1 \mathrm{mmol} / \mathrm{L}$ and a fasting plasma glucose concentration of $\geq 7.8 \mathrm{mmol} / \mathrm{L}$ were established as the criteria 
for the diagnosis of diabetes. In 1997, the American Diabetes Association (ADA) convened an expert committee to revisit these criteria [8]. The committee lowered the fasting plasma glucose (FPG) concentration for the diagnosis of diabetes from $\geq 7.8 \mathrm{mmol} / \mathrm{L}$ to $\geq 7.0 \mathrm{mmol} / \mathrm{L}$ but decided to retain the 2 -hour value of $\geq 11.1 \mathrm{mmol} / \mathrm{L}$ on the oral glucose tolerance test because a large number of epidemiological studies in the literature used this value to define diabetes and changing it "would be very disruptive".

However this 2hPG criterion and the FPG values defined as diagnostic of diabetes by the World Health Organization (WHO) [3] are not equivalent: approximately three quarters of subjects with diagnostic $2 \mathrm{hPG}$ concentrations ( $\geq 11.1 \mathrm{mmol} / \mathrm{L}$ ) have fasting glucose values below the level defined as diagnostic by the WHO $(7.8 \mathrm{mmol} / \mathrm{L})$.[9] Roughly $75 \%$ of subjects who participated in the NHANES II with diagnostic 2 -h values had fasting values $<7.8 \mathrm{mmol} / \mathrm{L}$.[9] Similarly, in relation to the ADA criteria, there is mounting evidence that there is a sizeable proportion of previously undiagnosed diabetic people with a $2 \mathrm{hPG}$ glucose $\geq 11.1 \mathrm{mmol} / \mathrm{L}$ but $\mathrm{FPG}<7.0 \mathrm{mmol} / \mathrm{L}$. This proportion varies in different populations and ranges from 32 to $72 \%$.[10-12] It has also been shown, from pooled analyses of 20 studies conducted in different European countries, that as many as one-third $(31 \%)$ of those who are diabetic, according to the $2 \mathrm{hPG}$, have normal fasting values $(<6.1 \mathrm{mmol} / 1)$ [12] and therefore, would not be detected by a screening procedure based essentially on fasting glucose measurements. In addition, fasting glucose is of little help in diagnosing impaired glucose tolerance (IGT) since evidence is accumulating that most people with IGT (from 54 to $67 \%$ ) have fasting glucose in the normal range $(<6.1 \mathrm{mmol} / \mathrm{L}) \cdot[12-14]$

It seems clear therefore, that not only are these cutoffs not equivalent in their definition of diabetes but the increased emphasis given by the expert committee [8] on the fasting values may not entirely be optimal. One strong argument for this is that it has been demonstrated that isolated post load hyperglycemia is a strong predictor of mortality $[10,15,16]$ and progression to diabetes, $[13,14]$ with prevention of progression to overt diabetes being possible in this group.[17] Based on the data presented above, the fasting criteria alone will be unable to detect this intermediate group of glucose intolerance. This is not just a consequence of the fasting cutoff, since it has also been shown, from the pooled data mentioned above [12], that even if the fasting glucose threshold is lowered to 5.5 $\mathrm{mmol} / \mathrm{l}$, (thus detecting 93\% of all those with diabetes diagnosed on the basis of $2 \mathrm{hPG}$ ), its ability to identify IGT (sensitivity) does not improve substantially. It has therefore been concluded that the FPG, while being useful to confirm the overtly diabetic state, misclassifies many peo- ple with abnormal glucose tolerance as being normal [18]. Since the latter group can be picked up by the $2 \mathrm{hPG}$ values, and adjustment of the fasting cut-off is of no additional benefit, it makes sense to use both measurements together in the in the definition of diabetes. We therefore evaluated their combined use for this purpose against mean levels of hemoglobin A1c (HbA1c) in our patient groups. This was compared with the use of single cut-offs for either the 2hPG (WHO) or the FPG (ADA) respectively in the definition of diabetes.

\section{Methods}

\section{Study population}

The study was a diabetes clinic-based study on glucose intolerance in a small group of resident Kuwaiti and expatriate population in Kuwait. A random sample $(n=43)$ of visitors referred from a general clinic with a clinical suspicion of glucose intolerance or diabetes (unexplained constitutional symptoms in an appropriate setting [for example first degree relatives with diabetes] or symptoms of diabetes such as polyuria \& polyphagia), aged 30 to 70 were included in the study. The OGTT was done by one of us (AP). Participants who were already treated for diabetes by insulin, oral anti-diabetic agents, or a physician-prescribed diet were excluded. Only 43 patients were recruited because we had allocated six months to data collection from the clinic. Patients are randomly allocated to each of five clinic physicians by the nursing staff and only new patients received by AP ( $\mathrm{n}=43$ by six months) were included in this study.

\section{Glucose, $\mathrm{HbAlc}$ and $\mathrm{BMI}$ measurements}

After 8-10 hours of overnight fasting, blood was collected for the measurement of FPG. Subsequently, a 75-g oral glucose (glucose tolerance test beverage, Fisher healthcare, Curtin Matheson Scientific, Houston, Texas, USA) tolerance test (OGTT) was performed and the plasma glucose level was measured 2 hours later (2hPG). The glucose levels were determined by means of the oxygen rate method employing a Beckman Coulter Oxygen Electrode (glucose oxidase method, Beckman Coulter Inc, Galway, Ireland). HbA1c was measured by the Beckman Synchron LX system(Beckman Instruments Inc, Fullerton CA, 92834-3100). This utilizes two cartridges, $\mathrm{Hb}$ and A1c to determine A1c concentration as a percentage of total $\mathrm{Hb}$. The hemoglobin is measured by a colorimetric method and the A1c concentration by a turbidimetric immunoinhibition method. The normal range for the HbA1c in our lab is $4.3-5.9 \%$. Weight and height were measured with participants wearing light clothing only, and the body mass index (BMI) was calculated as weight divided by the square of the height $\left(\mathrm{kg} / \mathrm{m}^{2}\right)$. 

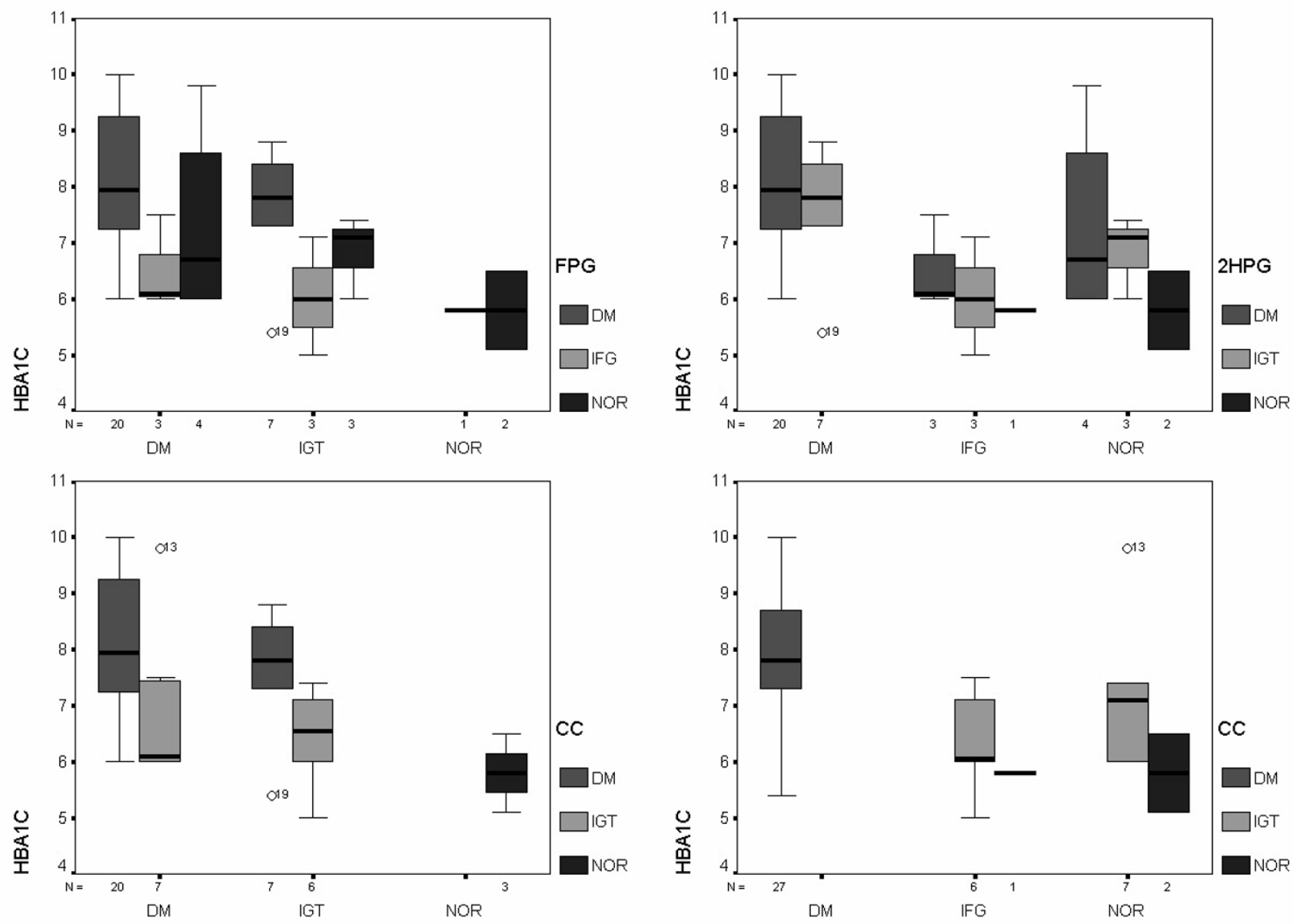

$2 \mathrm{HPG}$

FPG

Figure I

Boxplots of HbA I c by various diagnostic criteria. Subdivisions in each of these groups are depicted by different coloured boxes (red-diabetes, green-impaired, blue-normal). The box encloses the middle 50 percent of patients, and the median is represented as a horizontal line inside the box. The whiskers are lines that extend from the box to the highest and lowest values excluding outliers. The left and right plots depict 2-hour and FPG subdivisions respectively while the upper and lower plots depict comparisons against single and combined criteria clusters respectively ( $C C=$ combined criteria). There were two outliers (shown in the plots as circles with the patient number) and they were selected based on being more than I.5 box lengths from the ends of the box, but were included in the analysis in tables 1 \& 2. Diabetes was diagnosed in the same percentage (63\%) of patient's according to either of the single criteria or the combined criteria. One quarter of the diabetics by each single criterion were not diabetic by the other single criterion.

\section{Diagnosis of glycemic status}

a) Single criteria

Diabetes was diagnosed if the $2 \mathrm{hPG}$ was $11.1 \mathrm{mmol} / \mathrm{L}$ or greater, or the FPG was $7.0 \mathrm{mmol} / \mathrm{L}$ or greater. Impaired fasting glucose (IFG) was defined as a FPG between 6.1 $\mathrm{mmol} / \mathrm{L}$ and $6.9 \mathrm{mmol} / \mathrm{L}$ and IGT was diagnosed if the 2hPG was between $7.8 \mathrm{mmol} / \mathrm{L}$ and $11 \mathrm{mmol} / \mathrm{L}$.

\section{b) Our combined criteria}

For the combined criteria the upper limit for the FPG (specific test) was combined with the lower limit for the $2 \mathrm{hPG}$ (sensitive test). Normality was based on the $2 \mathrm{hPG}$ value $(<7.8 \mathrm{mmol} / \mathrm{L})$ so long as the fasting value was concordant $(<7 \mathrm{mmol} / \mathrm{L})$. In the same way, a fasting value was used to define diabetes $(\geq 7 \mathrm{mmol} / \mathrm{L})$ so long as the $2 \mathrm{hPG}$ value was concordant $(\geq 7.8 \mathrm{mmol} / \mathrm{L})$. A discordant fasting and $2 \mathrm{hPG}$ value defines combined criteria IGT (cIGT).

\section{Statistical methods}

All basic statistical analyses were done with Epi-info 6.04d [19] which was also the database with a cutoff for statistical significance of 0.05 . Graphics were charted on SPSS 
Table I: The mean $\mathrm{HbAlc}$ (and 95\% $\mathrm{Cl}$ for the difference between means) of 2 hPG or FPG subgroups within the combined criteria groups are reported. There were no significant differences in mean $\mathrm{HbAlc}$ between subgroups suggesting that the glycemic status within combined criteria groups was similar even for different FPG or $2 \mathrm{hPG}$ levels.

\begin{tabular}{|c|c|c|c|c|}
\hline & \multicolumn{4}{|c|}{ Combined Criteria } \\
\hline & \multicolumn{2}{|c|}{ Diabetes } & \multicolumn{2}{|c|}{ CIGT } \\
\hline & $\mathrm{n}$ & $\mathrm{HbAlc} \%$ & $\mathrm{n}$ & $\mathrm{HbAlc} \%$ \\
\hline \multicolumn{5}{|l|}{$2 \mathrm{hPG}$} \\
\hline Diabetic & 20 & a8.1 & 7 & b6.9 \\
\hline Impaired & 7 & a7.6 & 6 & $b_{6} 6.4$ \\
\hline \multicolumn{5}{|l|}{ FPG } \\
\hline Diabetic & 27 & 7.9 & & \\
\hline Impaired & 0 & - & 6 & c6.3 \\
\hline Normal & & & 7 & c7.1 \\
\hline
\end{tabular}

Difference in means ( $95 \% \mathrm{Cl}$ for difference): $\mathrm{a} 0.4 \%$ (-0.56-1.44), b $0.5 \%$ $(-0.95-2.03), c_{-}-0.8 \%(-2.2-0.6)$, all non-significantly different from zero.

version 10 for Windows, SPSS Inc, 1999. 95\% confidence intervals for the difference in means was calculated using Statgraphics Plus for Windows version 3.0, Statistical Graphics Corporation.

\section{Results}

The study population consisted of 33 men and 10 women with a mean age of $46.7(S D, 9)$ years. Mean BMI $(n=42$, anthropometric data of one patient was missed at initial visit) was $28.7 \pm 5 \mathrm{~kg} / \mathrm{M}^{2}$ (median 29, range 18.3-44.9). The results of sub-grouping of patients by different diabetes criteria are depicted in the figure and tables $1 \& 2$.

\section{Discussion}

Cutoff points such as those decided on by the ADA or $\mathrm{WHO}$, allow the comparison of a dichotomy of a test variable against a relevant clinical endpoint. The test result however should be considered diagnostic of diabetes only if it separates those at a low and high risk for a clinically important outcome such as a specific microvascular or macrovascular complication. For example, the inherent risk for retinopathy, as demonstrated in epidemiological studies, was the rationale behind the derivation of the $2 \mathrm{hPG}$ of $11.1 \mathrm{mmol} / \mathrm{L}$ criterion [20]. As the the HbA1c level at values $\geq 1 \%$ above the upper limit of normal (ULN) is associated with much greater development of progression of diabetic retinopathy or microalbuminuria, [21-24] its value correlates well with microvascular com- plications and was the standard in this study against which the various groups were evaluated. It may be pointed out here that although the use of the HbA1c in this way is useful (to define the glycemic status of patient groups with similar characteristics), it is not suitable for diabetes screening in individuals and cannot replace plasma glucose. It is true that the level of HbA1c is higher among diabetic than among nondiabetic persons, and among diabetic persons there is a correlation between HbA1c and various measures of glycemia, but this correlation seen in groups of patients does not hold for mildly hyperglycemic patients where the correlation is very poor, probably because glycemia proceeds at a slow rate and cannot reflect glycemia in toto [25]. When the HbA1c has been used as a screening test for individual patients, as expected, it has an unacceptably low sensitivity [26] that results in very poor discrimination of normality, IGT and diabetes in individual patients. It has a good specificity [26], however, allowing its use for assessment of glycemic control in the follow-up of diabetics.

Our results first demonstrate that IGT and diabetes by the 2hPG are unable to distinguish different levels of HbA1c (table 2), suggesting excessive overlap of these two groups. This is corroborated by other studies where approximately two thirds of individuals diagnosed as having diabetes by a 2hPG concentration of 11.1-13.3 mmol/L on an oral glucose tolerance test have normal HBA1C levels [27]. In addition to such normal HBA1C levels, less than $5 \%$ will have HbA1C levels $\geq 1 \%$ above the ULN that predicts an adverse outcome. Therefore, $95 \%$ of these patients will have met the American Diabetic Association's goal HbA1c value of less than the upper limit of normal + $1 \%$ [28] and will be treated with diet and exercise rather than pharmacological agents. This is the same treatment that would be offered to patients with impaired glucose tolerance, (i.e., those whose $2 \mathrm{hPG}$ concentrations on an oral glucose tolerance test are $7.8-11.0 \mathrm{mmol} / \mathrm{L}$ ). This is also corroborated by pooled data in 16 studies presented by Davidson et al [7] where patients with an HbA1c level $\geq 1 \%$ above the ULN have been shown to have a very high probability of meeting the $2 \mathrm{hPG}$ criteria for diabetes (>95\%) while at the same time (as noted above) most of the subjects with diagnostic 2 hPG do not have a HbA1c $\geq$ $1 \%$ of the ULN and approximately two-thirds would actually have a normal HbA1c.[29]

Secondly, we have also demonstrated that the HbA1c in those with IFG is very distinct from diabetics (by FPG, table 2). This is because a lot of the IFG group actually have normal glucose tolerance, making the separation from diabetics even more. This conclusion is supported by a 6 year prospective study of 1342 non-diabetic white Dutch individuals aged 50-75 years who had an OGTT at baseline and where IFG was present in only $28 \%$ of those with 
Table 2: The difference in mean HbAlc and $95 \%$ confidence intervals for the difference between the means for the fasting and impaired subgroups of all three classification methods are reported. The implications of these differences are discussed in the text.

\begin{tabular}{|c|c|c|c|c|c|}
\hline & \multicolumn{4}{|c|}{ Glycemic status } & \multirow{3}{*}{$\begin{array}{l}\text { Difference and } 95 \% \mathrm{Cl} \\
\text { for difference in means }\end{array}$} \\
\hline & \multicolumn{2}{|c|}{ Diabetes } & \multicolumn{2}{|c|}{ IGT/IFG } & \\
\hline & $\mathrm{n}$ & $\mathrm{HbAlc} \%$ & $\mathrm{n}$ & $\mathrm{HbAlc} \%$ & \\
\hline $2 \mathrm{hPG}$ & 27 & 7.8 & 13 & 7.1 & $0.7(-0.15-1.57), p=0.1$ \\
\hline FPG & 27 & 7.9 & 7 & 6.2 & $1.7(0.79-2.69), p=0.0007$ \\
\hline Combined Criteria & 27 & 7.9 & 13 & 6.7 & $1.2(0.4-2), p=0.003$ \\
\hline
\end{tabular}

IGT but was absent in $92 \%$ of those without IGT $(28 \%$ sensitivity, 92\% specificity).[30] Based on the usual prevalence of IGT and diabetes in communities, two-thirds of those with IFG can be expected to have a normal OGTT. This conclusion is also supported by the data presented by Davidson et al [31], where only about $13 \%$ of individuals diagnosed to have IFG by virtue of a FPG of 6.1-6.9 $\mathrm{mmol} / \mathrm{L}$ will have an abnormal HbA1c. Less than $1 \%$ will have HbA1c levels $\geq 1 \%$ above the ULN. Therefore $87 \%$ of these persons should require no intervention. These authors (adapted from the table) also reveal that patients with a normal HbA1c have a very low probability (3\%) of meeting the fasting threshold of $7 \mathrm{mmol} / \mathrm{L}$. (This is in stark contrast to the people with FPG concentrations of 7.0 or more, two-thirds of whom have abnormal glycated hemoglobin levels [31])

What are the implications of this? It is clear that the FPG $<7 \mathrm{mmol} / \mathrm{L}$ provides no reliable information on whether an individual is normal or is at risk from future diabetes or future cardiovascular, eye or kidney disease related to diabetes.[18] In a similar fashion, the $2 \mathrm{hPG}$ provides poor discrimination of those at future risk from the overtly diabetic patients with ongoing risk. This is again confirmed by the Funagata Diabetes Study in Japan, where the hazard ratios for all cause and cardiovascular mortality were higher for subjects diagnosed with diabetes according to the FPG than for subjects diagnosed according to the $2 \mathrm{hPG}$. However subjects with IGT had a higher risk of cardiovascular mortality than subjects with IFG.[32] These observations suggest that a diagnostic fasting value represents a level of glycemia that provides a high level of clinical certainty that the patient does indeed have diabetes, especially if it is elevated on two occasions [20], whereas the 2-hour criterion does not. In the same vein, a normal $2 \mathrm{hPG}$ provides a high level of clinical certainty that a patient needs no intervention, whearas the fasting criterion does not. It then becomes clear that to diagnose normality, impaired glucose tolerance and diabetes, we need a combination of these two criteria: One that favours sensitivity to exclude diabetes and the other that favours specificity to diagnose diabetes. The same result can not be achieved by adjusting cut-offs of single measurements.

We acknowledge that our study is limited by the small number of participants. It is possible that in table 2, nonsignificance with the $2 \mathrm{hPG}$ could be related to the small number of patients. Nevertheless, the analysis in our combined criteria group had the same number of patients and this was even less in the FPG group but both reached statistical significance. In table 1 , there were even smaller numbers compared in the cIGT groups, and it is possible that larger numbers may have attained a significant difference. This however seems unlikely for the FPG group where the mean difference was almost $1 \%$ higher in the normal group. We have cited the data in the literature extensively with our results, and the results from larger studies are not divergent from our data. Certainly, a larger trial is warranted to confirm the validity of this diagnostic approach.

\section{Conclusions}

The $2 \mathrm{hPG}[\geq 7.8 \mathrm{mmol} / \mathrm{L}]$ is poorly specific for diabetes and only its combination with a FPG $\geq 7 \mathrm{mmol} / \mathrm{L}$ can be considered diagnostic of diabetes. In the same vein, a FPG $[<7 \mathrm{mmol} / \mathrm{L}]$ is poorly sensitive for diabetes and only its combination with a $2 \mathrm{hPG}<7.8$ can be considered normality. A discordant result (usually means FPG $<7 \mathrm{mmol} /$ 
Table 3: Proposed combined criteria for the definition diabetes and impaired glucose tolerance. As expected in view of the small cohort, $100 \%$ of our patients with IGT by combined criteria had IGTI. This would mean that FPG diabetics and $2 \mathrm{hPG}$ normals will have $100 \%$ concordance with the combined criteria diabetics and normals respectively (see figure). In larger cohorts there may be a minor discordance of FPG diabetics and $2 \mathrm{hPG}$ normals with the combined criteria (IGT2).

\section{Combined diagnostic criteria for diabetes}

\section{Diabetes \\ Impaired glucose \\ tolerance}

Normal
$\mathrm{FPG} \geq 7 \mathrm{mmol} / \mathrm{L}$ AND 2-hour glucose $\geq 7.8 \mathrm{mmol} / \mathrm{L}$

IGTI: FPG $<7 \mathrm{mmol} / \mathrm{L}$ AND 2-hour glucose $\geq 7.8 \mathrm{mmol} / \mathrm{L}$ Or IGT2:FPG $\geq 7 \mathrm{mmol} / \mathrm{L}$

AND 2-hour glucose $<7.8 \mathrm{mmol} / \mathrm{L}$

FPG $<7 \mathrm{mmol} / \mathrm{L}$ AND 2-hour glucose $<7.8 \mathrm{mmol} / \mathrm{L}$
$\mathrm{L}$ and $2 \mathrm{hPG} \geq 7.8 \mathrm{mmol} / \mathrm{L}$ as the reverse is uncommon) should then represent cIGT. Our results also clearly indicate that a combination of both criteria do complement each other in the definition of diabetes and propose these criteria (outlined in table 3 ) for the definition of diabetes, glucose intolerance or euglycemia. It can be estimated from the data in the literature that if these combined criteria are applied in a population, three-fourths of those with IFG will be re-diagnosed as normal by the combined criteria and $10 \%$ of those with normal FPG will be re-diagnosed as cIGT by the combined criteria. Assuming a 5\% prevalence of diabetes and $10-11 \%$ prevalence of IFG in the community, equal numbers of patients with either IFG or normal FPG will switch categories by the combined criteria. That this switch is appropriate, is indicated by the similar mean HbA1c of the single cutoff subgroups within our combined categories in table 1 , but will require larger studies to confirm this. We look forward to the results of prospective evaluation of this proposal in larger population based studies.

\section{Competing interests}

None declared.

\section{References}

I. Valleron AJ, Eschwege E, Papoz, Rosselin GE: Agreement and discrepancy in the evaluation of normal and diabetic oral glucose tolerance test. Diabetes 1975, 24:585-93

2. National Diabetes Data Group: Classification and diagnosis of diabetes mellitus and other categories of glucose intolerance. Diabetes 1979, 28:1039-57

3. World Health Organization Expert Committee on Diabetes Mellitus: Second Report: Geneva, Switzerland: World Health Organization, Technical Report 646. 1980

4. Jarrett RJ, Keen H: Hyperglycemia and diabetes mellitus. Lancet 1976, 2:1009-12

5. Sayegh HA, Jarrett RJ: Oral glucose-tolerance test and the diagnosis of diabetes: results of a prospective study based on the Whitehall survay. Lancet 1979, 2:43I-3

6. Pettitt DJ, Knowler WC, Lisse JR, Bennett PH: Development of retinopathy and proteinuria in relation to plasma-glucose concentrations in Pima Indians. Lancet 1980, 2:1050-2

7. Davidson MB, Peters AL, Schriger DL: An alternative approach to the diagnosis of diabetes with a review of the literature. Diabetes Care 1995, 18:1065-7|
8. Committee Expert: Report of the expert committee on the diagnosis and classification of diabetes mellitus. Diabetes Care 1997, 20:1183-97

9. Harris MI, Hadden WC, Knowler WC, Bennett PH: Prevalence of diabetes and impaired glucose tolerance and plasma glucose levels in U.S. population aged 20-74 yr. Diabetes 1987, 36:52334

10. Barrett-Connor E, Ferrara A: Isolated postchallenge hyperglycemia and the risk of fatal cardiovascular disease in older women and men: the Rancho Bernardo Study. Diabetes Care 1998, 2 I:1236-39

II. Shaw JE, de Courten M, Boyko EJ, Zimmet PZ: Impact of new diagnostic criteria for diabetes on different populations. Diabetes Care 1999, 22:762-6

12. The DECODE Study Group on behalf of the European Diabetes Epidemiology Group: Is fasting glucose sufficient to define diabetes? Epidemiological data from 20 European studies. Diabetologia 1999, 42:647-54

13. Vaccaro O, Ruffa G, Imperatore G, lovino V, Rivellese AA, Riccardi G: Risk of diabetes in the new diagnostic category of impaired fasting glucose. Diabetes Care 1999, 22:1490-93

14. Shaw JE, Zimmet PZ, De Couten M, Dowse GK, Chiston P, Gareboo H, Hemraj F, Fareed D, Tuomilehto J, Alberti KG: Impaired fasting glucose or impaired glucose tolerance? Diabetes Care 1999, 22:399-402

15. The DECODE Study Group on behalf of the European Diabetes Epidemiology Group: Glucose tolerance and mortality: Comarison of WHO and American Diabetes Association diagnostic criteria. Lancet 1999, 354:617-21

16. Shaw JE, Hodge AM, de Courten M, Chitson P, Zimmet PZ: Isolated post-challenge hyperglycemia confirmed as a risk factor for mortality. Diabetologia 1999, 42:1050-54

17. Olga Vaccaro, Gianluca Ruffa, et al: Is There Any Use for the Oral Glucose Tolerance Test? Diabetic Care 2000, 23:7| 4-15

18. Gerstein HC: Fasting Versus Postload Glucose Levels: Why the controversy? Diabetes Care. 200I, 24:1855-7

19. Dean AG, Dean JA, Coulombier D, et al: Epi Info version 6: A word-processing, database and statistics program for public health on IBM-compatible microcomputers. Centers for Disease Control and Prevention, Atlanta, Georgia, 1995

20. David McCance R, Robert Hanson L, et al: Which Test for Diagnosing Diabetes? Diabetes Care 1995, I 8: 1042-44

21. The Diabetes Control and Complications Trial Research Group: The relationship of glycemic exposure (HbAIC) to the risk of development and progression of retinopathy in the Diabetes Control and Complications Trial. Diabetes 1995, 44:968-83

22. Krowleski AS, Laffel LMB, Krowleski M, Quinn M, Warram JH: Glycosylated hemoglobin and the risk of microalbuminuria in patients with insulin-dependent diabetes mellitus. $N$ Engl I Med 1995, 332:125I-5

23. Ohkubo $\mathrm{Y}$, Kishikawa $\mathrm{H}$, Araki E, et al: Intensive insulin therapy prevents the progression of diabetic micro vascular complications in Japanese patients with non-insulin-dependent diabetes mellitus: a randomized prospective 6-year study. Diabetes Res Clin Pract 1995, 28:103-17 
24. Tanaka $Y$, Atsumi $Y$, Matsuoka K, Onuma T, Tohjima T, Kawamori R: Role of glycemic control and blood pressure in the development and progression of nephropathy in elderly Japanese NIDDM patients. Diabetes Care 1998, 21:1 | 6-20

25. Service F): Correlation between glycemia and glycated hemoglobin. Comprehensive Therapy 1990, 16:33-40

26. Guillausseau PJ, Charles M-A, Paolaggi F, Timsit J, Chanson P, Peynet J, Godard V, Eschwege E, Rousselet F, Lubetzki J: Comparison of $\mathrm{HbAl}$ and fructosamine in diagnosis of glucose-tolerance abnormalities. Diabetes Care 1990, I 3:898-900

27. Mayer Davidson B, David Schriger L, et al: Revisiting the Oral Glucose Tolerance Test Criterion for the Diagnosis of Diabetes, J Gen Intern Med 2000, 1 5:55I-55

28. American Diabetic Association: Standards of medical care for patients with diabetes mellitus. Diabetes Care 1999, 22:S32-4I

29. Davidson MB, Schriger DL, Peters AL, Lorber B: Revisiting the oral glucose tolerance test criterion for the diagnosis of diabetes. J Gen Intern Med 2000, 15:55।-555

30. de Vegt F, Dekker JM, Jager A, Hienkens E, Kostense PJ, Stehouwer $C D$, Nijpels G, Bouter LM, Heine RJ: Relation of impaired fasting and postload glucose with incident type 2 diabetes in a Dutch population: The Hoorn Study. JAMA 200I, 285:2 109-13

31. Davidson MB, Schriger DL, Peters AL, Lorber B: Relationship between fasting plasma glucose and glycosylated hemoglobin: potential for false-positive diagnoses of type 2 diabetes using new diagnostic criteria. JAMA 1999, 28 I:1203-10

32. Tominaga M, Eguchi H, Manaka H, Igarashi K, Kato T, Sekikawa A: Impaired glucose tolerance is a risk factor for cardiovascular disease, but not impaired fasting glucose. The Funagata Diabetes Study. Diabetes Care 1999, 22:920-4

Publish with BioMed Central and every scientist can read your work free of charge

"BioMedcentral will be the most significant development for disseminating the results of biomedical research in our lifetime."

Paul Nurse, Director-General, Imperial Cancer Research Fund

Publish with BMC and your research papers will be:

- available free of charge to the entire biomedical community

- peer reviewed and published immediately upon acceptance

- cited in PubMed and archived on PubMed Central

- yours - you keep the copyright
BioMedcentral.com editorial@biomedcentral.com 